\title{
Considerações acerca dos sistemas adotados pela lei №. 11419/2006 de informatização do processo judicial
}

\author{
Considerations about the systems adopted by law no. 11419/2006 computerization of the \\ judicial process
}

\author{
Danilo Silva Bittar ${ }^{1}$
}

\section{Resumo}

Com o advento da Lei no. 11.419/2006, um grande passo foi dado para a implantação do processo eletrônico no Brasil, todavia, alguns pontos referentes à nova legislação merecem atenção, sob pena de fracasso do modelo idealizado pelo legislador pátrio. Analisar-se-á, aqui, a questão concernente aos sistemas eletrônicos de identificação, credenciamento e destinados para a prática de atos processuais adotados, bem como serão apresentadas críticas e apontadas controvérsias instituídas pelo diploma legal mencionado. Além disso, temas relevantes à viabilização da informatização do processo judicial serão abordados, tais como a absoluta necessidade de identificação mediante assinatura eletrônica baseada em certificado digital, além da não obrigatoriedade de credenciamento prévio, mediante comparecimento pessoal do interessado, junto ao Poder Judiciário e, por fim, quanto à indispensabilidade de adoção de uma plataforma eletrônica única para a transmissão de petições e prática de atos processuais.

Palavras Chave: Lei no. 11.419/2006; Informatização do processo judicial; Processo eletrônico.

\section{Abstract}

With the enactment of Law $\mathrm{n}$ - $11.419 / 2006$, a major step was taken to digitize the justice process in Brazil. However, some points regarding the new legislation require attention to ensure that the model set out in the law does not fail. This article will examine the issues surrounding the informatics systems of identification, accreditation and those intended for processing legal acts as designated in the aforementioned law, and present criticisms and controversies about these systems. In addition, the feasibility of the computerization of the judicial process will be examined, exploring salient topics such as the absolute need for identification by electronic signature based on digital certificates; the obligatory previous accreditation by the individuals involved in the electronic process before the judiciary power; and

\footnotetext{
${ }^{1}$ Acadêmico do $5^{\circ}$ ano do curso de Direito da Universidade Estadual de Londrina - UEL. dsbittar@gmail.com
} 
finally the indispensability of adopting a single electronic platform for the submission of petitions and the practice of legal actions.

Keywords: E-justice; Dematerialization of legal process; Digitizing the justice system.

\section{Introdução}

A Lei no. 11.419/2006, que dispõe sobre a informatização do processo judicial², embora tenha surgido em momento posterior ao do início da utilização do processo eletrônico no Brasil, certamente representou um grande avanço no sentido de ampliação e regulamentação dessa questão.

Em sua estrutura, a legislação em comento definiu, em linhas gerais, como ocorrerá a prática de atos processuais por meio eletrônico, dispondo sobre a transmissão de petições, as citações e intimações, Diário da Justiça Eletrônico, entre outros pontos. Além disso, por óbvio, tratou de estabelecer como se dará a informatização do processo judicial propriamente dita, dispondo em seu primeiro capítulo ${ }^{3}$ quanto às "formas de identificação"

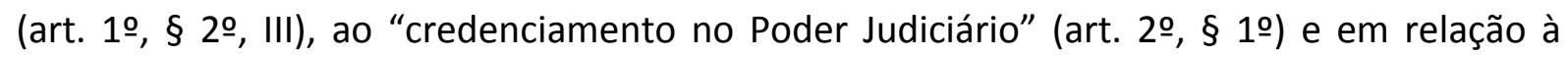
"prática de atos processuais em geral por meio eletrônico" (art. 2ํ, caput), que são o objeto do presente estudo.

Denominaram-se, aqui, as disposições mencionadas como sistemas de identificação, sistemas de credenciamento e sistemas destinados para a prática de atos eletrônicos; adotando-se, para tanto, o vocábulo sistema no sentido de método, ou ainda, forma. Isso significa dizer que serão estudados no presente os meios adotados pela lei com o fim de identificar, credenciar e praticar atos processuais por meio eletrônico.

Note-se que, a doutrina pátria, de modo geral, tece diversas críticas em relação à Lei no. 11.419/2006 num todo, entretanto, busca-se neste estudo examinar justamente a parte inicial do referido diploma legal, tendo em vista que, caso frustrada a virtualização do procedimento, de nada valerão as demais disposições, como aquelas acerca da comunicação eletrônica dos atos processuais ${ }^{4}$, por exemplo.

\footnotetext{
2 BRASIL. Lei no 11.419, de 19 de dezembro de 2006. Disponível em: <www.planalto.gov.br/ccivil_03/_ato2004-2006/2006/lei/l11419.htm>. Acesso em 23 out. 2010.

${ }^{3}$ Capítulo I "Da informatização do processo judicial”, arts. 10 a 3ㅇ.

${ }^{4}$ Título do Capítulo II da Lei no 11.419/2006.
} 
Assim, a princípio, analisar-se-á o que é cada um dos sistemas admitidos na legislação e, posteriormente, serão apontadas críticas relativas à legislação, visando aprimorar a discussão sobre os dispositivos mais controvertidos acerca do processo eletrônico ${ }^{5}$ atualmente.

\section{Os sistemas previstos na lei no. 11.419/2006}

Sistemas de Identificação

A fim de se compreenderem as críticas a serem tecidas em face da Lei $\mathrm{n}$ ㅇ. 11.419/2006 no que tange aos seus sistemas eletrônicos de identificação, de credenciamento e daqueles destinados para a prática de atos processuais, faz-se necessário, a princípio, compreender o que é cada um dos referidos sistemas.

Em primeiro lugar, os sistemas de identificação podem ser considerados aqueles descritos no art. 1으 $\S 2$ 으, III, que se destinam, em síntese, a garantir a paridade absoluta entre aquele que diz que realiza e quem efetivamente pratica o ato processual pelo meio eletrônico.

Em outras palavras, como só há sentido em se pensar em processo eletrônico caso seja possível se estabelecer com certeza a identidade do remetente de determinada petição, mostram-se necessários meios que assegurem essa identificação ao destinatário. Assim, o papel principal destes sistemas é justamente preservar a lisura na transmissão de documentos eletrônicos.

A lei em comento admite no dispositivo legal mencionado dois sistemas de identificação mediante a utilização de assinaturas eletrônicas, quais sejam, a assinatura digital baseada em certificado digital emitido por Autoridade Certificadora credenciada, na forma de lei específica (art. 1으 $\S 2$ 으, III, "a") e a assinatura obtida mediante cadastro de usuário no Poder Judiciário, conforme disciplinado pelos órgãos respectivos (art. 1ํ, § 2으, III, "b").

Há certa polêmica neste ponto, tendo em vista que Almeida Filho (2010, p. 144) posiciona-se no sentido de que o dispositivo legal em tela não autoriza duas formas de

\footnotetext{
5 Assim como noticiado por Wambier (2007, p. 290), "não se desconhece a variedade de termos frequentemente utilizados para designar tal fenômeno (além de 'eletrônico', são usadas, por exemplo, expressões como digital, e-proc, telemático, virtual, informático etc.). Utilizaremos, commodatis causa, o termo do legislador".
} 
identificação como ora se sustenta. De acordo com ele, a interpretação mais abalizada do

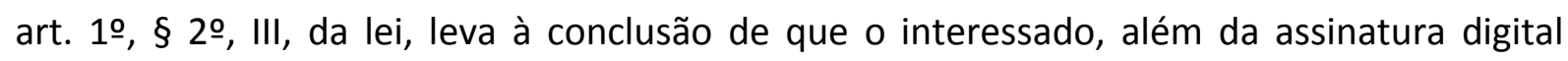
(hipótese da alínea "a"), deve também possuir um cadastro junto ao Poder Judiciário (alínea "b"), ou seja, não se tratam de dois sistemas, mas sim de um único composto por uma "duplicidade de requisitos".

Todavia, esse entendimento parece isolado na doutrina pátria, além do que cai por terra quando facilmente se constata, atualmente, a existência de diversas plataformas eletrônicas de transmissão de petições (que serão tratadas abaixo), como o e-Proc ${ }^{6}$, por exemplo, que utilizam o sistema usuário-senha sem exigir a assinatura digital. De qualquer forma, para os fins do presente estudo, se adotará a duplicidade de sistemas de identificação, pelas razões expostas acima.

\section{Sistemas de Credenciamento}

Segundo a Lei no. 11.419/2006 em seu art. 2으, caput, § 1으 e 3으, a fim de o interessado pratique atos processuais por meio eletrônico, será necessário um credenciamento prévio junto ao respectivo órgão do Poder Judiciário. Ainda, de acordo com o referido dispositivo, tal credenciamento se dará obrigatoriamente mediante o comparecimento pessoal do interessado.

Para que se viabilize o credenciamento mencionado são necessários os sistemas de credenciamento, que funcionam como uma espécie de cadastro, criados e gerenciados pelos tribunais, possibilitando aos interessados o acesso aos sistemas destinados para prática de atos processuais a serem tratados no item a seguir.

Em que pese alguns autores defendam que esse credenciamento junto ao Poder Judiciário seja uma prática "salutar", como Almeida Filho (2010, p. 166), a doutrina majoritária perfilha entendimento no sentido de que tal exigência é incompatível com a proposta da informatização do processo judicial, conforme veremos.

\section{Sistemas Destinados para a Prática de Atos Processuais}

6 O e-Proc é a plataforma de processo eletrônico dos Juizados Especiais Federais e pode ser acessado em:
<https://jef.jfrs.jus.br/eprocV2/>. 
Por fim, a lei de informatização do processo judicial estabelece em seu art. 2ㅇ, $\S 2 \circ$, que aos interessados credenciados nos sistemas mencionados no item anterior serão garantidos meios de acesso a outros sistemas, quais sejam, os sistemas destinados para prática de atos processuais.

Os referidos sistemas são as plataformas de processo eletrônico, onde se praticam os atos processuais propriamente ditos. É através deles que se dá a transmissão das petições, bem como se visualizam as decisões judiciais e se verifica o andamento das demandas virtuais.

Sistemas de Credenciamento $\mathrm{x}$ Sistemas Destinados para a Prática de Atos Processuais

Imperioso se registrar, ainda, que se nota dentre os doutrinadores certo equívoco quando da diferenciação entre os sistemas de credenciamento e as plataformas de processo eletrônico previstos na lei.

Com efeito, em determinados casos, autores tratam os dois sistemas como um só, todavia, sem razão, eis que, nos termos do art. 2으 § 2으, mediante o credenciamento será garantido o acesso ao sistema eletrônico para a prática de atos processuais. Assim, verificase que, muito embora em determinados casos o credenciamento e a prática de atos ocorram em um único sítio eletrônico, a existência de dois sistemas parece clara: uma base de dados, ou ainda, um cadastro e um programa onde ocorrerá a efetiva transmissão de documentos eletrônicos e outros atos.

Estabelecidos os conceitos dos sistemas que serão tratados no presente estudo, vejamos as críticas no que se referem aos métodos de identificação, credenciamento e destinados à prática de atos processuais previstos na legislação em comento.

\section{Considerações acerca dos sistemas adotados pela legislação}

Conforme salientado acima, no que se refere aos sistemas de identificação do

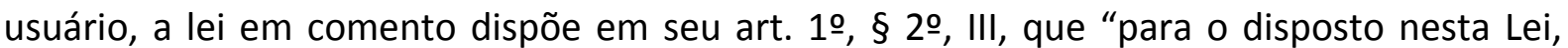
considera-se assinatura eletrônica as seguintes formas de identificação inequívoca do 
signatário: a) assinatura digital baseada em certificado digital emitido por Autoridade Certificadora credenciada, na forma de lei específica; b) mediante cadastro de usuário no Poder Judiciário, conforme disciplinado pelos órgãos respectivos".

Todavia, conforme restará esclarecido, houve um equívoco por parte do legislador ao permitir o sistema de assinatura eletrônica mediante o simples cadastro do usuário junto ao respectivo órgão do Poder judiciário, senão vejamos.

Assinatura eletrônica, assinatura digital, certificado digital e assinatura obtida mediante cadastro no Poder Judiciário

Para a melhor compreensão do dispositivo mencionado (art. 1으 $\S 2$ 으, III, do diploma legal em questão), é necessário analisar-se os conceitos de alguns dos termos utilizados pela lei, tais como assinatura eletrônica, assinatura digital, certificado digital e assinatura obtida mediante cadastro junto ao Poder Judiciário.

Em primeiro lugar, a assinatura eletrônica "é um modo de garantir que o documento é proveniente do seu autor e que seu conteúdo está íntegro" (ALVIM; CABRAL JUNIOR, 2007, p. 20). Nas palavras de Calmon (2008, p. 25), "assinatura eletrônica diz respeito a toda e qualquer forma de identificação efetuada por meio eletrônico", ou seja, é o gênero do qual a assinatura digital e outras são espécies.

Por sua vez, a assinatura digital é "um método que garante que determinada mensagem não seja alterada durante seu trajeto" (CALMON, 2008, p. 26). De acordo com o glossário do ITI (Instituto Nacional de Tecnologia da Informação), assinatura digital é "uma modalidade de assinatura eletrônica, resultado de uma operação matemática que utiliza criptografia e permite aferir, com segurança, a origem e a integridade do documento" (SOARES, 2010, p. 46).

Todavia, nos termos da lei em comento, não basta, para fins de identificação, que o interessado se utilize de uma simples assinatura digital, devendo esta ser certificada digitalmente por entidade definida em lei específica. Isto significa dizer que, ainda que o advogado se utilize uma assinatura digital, é imprescindível a existência de um certificado que garanta a certeza da titularidade daquela assinatura.

Daí surge a figura do certificado digital, que nada mais é que um documento eletrônico que permite a identificação segura do autor de uma mensagem enviada por meio 
virtual. Tal documento eletrônico é expedido por entidade pública definida nos termos da Medida Provisória no. 2.200-2/2001 e pode ser conceituado como a assinatura digital de um terceiro de confiança atestando ser o declarante quem ele realmente diz ser.

Segundo Menke (2003), as assinaturas certificadas digitalmente "servem para agregar os valores confiança e segurança às comunicações e negócios veiculados em ambiente virtual, especialmente na internet", sendo que, de acordo com Rohrmann (2008, p. 30), os efeitos legais de um documento assinado e consequentemente certificado digitalmente são os mesmos da assinatura civil, conforme dispõe o art. 10, da Medida Provisória citada 7 .

Importante se destacar aqui, conforme salientado por Calmon (2008, p. 29), que para obtenção de um certificado digital é imprescindível que o advogado compareça pessoalmente ao local determinado pela autoridade, devendo identificar-se fisicamente, inclusive munido de fotografia, para cadastro, funcionando como uma espécie de carteira de identidade virtual. Além disso, a certificação digital, segundo o autor em questão, revela a tendência não só brasileira, mas também mundial no que se refere à segurança de transações e envio de documentos por meio eletrônico.

Por fim, a assinatura obtida mediante cadastro do usuário no Poder Judiciário se trata de outra forma de assinatura eletrônica e é disciplinada conforme a conveniência de cada um dos respectivos tribunais que a utilizará (ALVIM; CABRAL JUNIOR, 2007, p. 22). A doutrina, de modo geral, a denomina como sistema usuário-senha.

Simples cadastro do usuário no órgão do Poder Judiciário como sistema de identificação.

Estabelecidas as premissas delineadas no item anterior, é fácil se identificar a incongruência do mencionado art. 1으, § 2으, III, da Lei no․ 11.419/2006 ao permitir outra forma de identificação que não a assinatura digital certificada.

\footnotetext{
7 “Art. 10 § 1ํ As declarações constantes dos documentos em forma eletrônica produzidos com a utilização de processo de certificação disponibilizado pela ICP-Brasil presumem-se verdadeiros em relação aos signatários, na forma do art. 131 da Lei no 3.071, de 10 de janeiro de 1916 - Código Civil". BRASIL. Medida Provisória 2.200-2/2001, de 24 de agosto de 2001. Disponível em: <http://www.planalto.gov.br/ccivil_03/mpv/ Antigas_2001/2200-2.htm>. Acesso em 23 out. 2010.
} 
Ora, se há lei específica que instituiu um sistema composto por entidades destinadas a "garantir a autenticidade, a integridade e a validade jurídica de documentos em forma eletrônica" (art. 1ํㅡ, da Medida Provisória no. 2.200-2/2001), qual a razão de se permitir a utilização de um sistema de simples cadastro usuário-senha desprovido de qualquer segurança?

O permissivo do mencionado dispositivo legal criou um mecanismo de identificação conflitante com a legislação concernente à certificação digital, motivo pelo qual não pode ser considerado seguro, ou, pelo menos, o mais seguro. Como se sabe, a assinatura digital é, na verdade, "o único meio legalmente aceito para que pessoas possam assinar documentos eletrônicos com a mesma validade jurídica da assinatura de próprio punho, com força jurídica sedimentada pela M.P. 2.200 de fevereiro de 2001" (CUNHA; TATO, 2010, p. 120).

Assim, a nova sistemática admitida (usuário-senha) que se destina tão-somente a validar o ingresso do usuário no sistema não preserva adequadamente as informações que tramitam no meio eletrônico (o que ocorreria apenas mediante a assinatura certificada digitalmente), acarretando insegurança e, consequentemente, abala a credibilidade do processo judicial virtual (PAULA, 2010, p. 84).

Com efeito, Almeida Filho (2010, p. 279), embora sustente a ausência de duplicidade de sistemas de identificação, rechaça a hipótese de utilização do sistema usuário-senha, afirmando categoricamente que "não se pode, em procedimento eletrônico, nos dias de hoje, adotar login e senha". De acordo com ele, utilizando-se a certificação digital não há como existir fraude, "pelo menos por enquanto, quanto à assinatura aposta no documento. Contudo, em se tratando de login e senha, que ficam registrados nos computadores - e esta realidade não pode ser descartada - até mesmo sentenças poderão ser proferidas fraudulentamente" (ALMEIDA FILHO, 2010, p. 280).

Reinaldo Filho (2007, p. 1), perfilhando entendimento no mesmo sentido, denomina a assinatura digital (alínea "a") como um tipo de sistema de identificação "avançado", enquanto designa aquele previsto na alínea "b" do dispositivo legal em tela como sistema "não avançado".

Atheniense (2010, p. 124), por sua vez, afirma que essa permissão legal de assinatura eletrônica sem certificação digital "impacta em menor credibilidade quanto à autenticidade, à integridade e à irretratabilidade do usuário no momento da transmissão de 


\section{Considerações acerca dos sistemas adotados pela lei №. 11419/2006 de informatização do processo judicial}

dados por meio eletrônico", uma vez que tal sistemática permite a alteração no documento sem deixar vestígios, restando claro que a utilização dos sistemas usuário-senha por parte dos órgãos do judiciário não pode ser aceito como a forma mais segura de se identificar os participantes do processo eletrônico.

Não bastasse, a controvérsia resta ainda mais evidente quando se constata, conforme noticiado por Calmon (2008, p. 79), que a própria lei não exige certificação digital para a identificação do advogado, fragilizando sua comunicação, "mas exige essa mesma certificação para os próprios tribunais, que terão que se submeter às regras da ICP-Brasil para publicarem o diário eletrônico", consoante art. 4ํ, § 1ํ, da Lei ํo. 11.419/2006.

Da mesma forma, o art. 20 da lei ora estudada, ao estabelecer que "a procuração pode ser assinada digitalmente com base em certificado emitido por Autoridade Certificadora credenciada, na forma da lei específica", admitiu, mais uma vez, que a certificação digital é o método mais seguro de identificação .

Assim, parece evidente que, caso o Poder Judiciário realmente pretenda que a lei em questão seja efetiva, é imprescindível que se adotem sistemas reconhecidamente seguros de identificação dos usuários, sendo inadmissível se pensar em outro método que não a assinatura certificada digitalmente, como autorizado na alínea " $b$ ", do art. 1ㅇ, § 2ำ, III, da Lei no. 11.419/2006.

A despeito disso, conforme leciona Paula (2010, p. 87), levando-se em conta o intuito do legislador em garantir a utilização dos sistemas informatizados de tramitação judicial por aqueles interessados que não possuem assinaturas eletrônicas certificadas, este "deveria, ao menos, assinalar como obrigatória, a utilização de recursos seguros de autenticação de documentos, como por exemplo a criptografia", o que, todavia, também não ocorreu.

Imperioso se destacar, ainda, que o Superior Tribunal de Justiça já resolveu essa questão através da Resolução no. $1 / 2010^{9}$, que em seu art. 18 , caput e $\S 1$, estabelece que o encaminhamento de petições ao referido Tribunal Superior depende da utilização pelo

\footnotetext{
8 Note-se que, no mencionado dispositivo, a lei em questão referiu-se expressamente à Medida Provisória noㅡ $2.200 / 2001$.

9 BRASIL. Superior Tribunal de Justiça. Resolução n. 1, de 10 de fevereiro de 2010. Diário da Justiça Eletrônico [do] Superior Tribunal de Justiça, Brasília, DF, 11 fev. 2010. Disponível em: <https://ww2.stj.jus.br/infProc/init?\#>. Acesso em: 23 out. 2010.
} 
interessado da sua identidade digital, a ser adquirida perante a ICP - Brasil, isto é, de sua assinatura digital certificada, nos termos do que foi defendido acima ${ }^{10}$.

Em nível internacional, Portugal foi um dos primeiros países a se adequar à implantação do processo eletrônico, sobretudo na produção de atos processuais por esse meio, mediante a assinatura eletrônica com a utilização de certificação digital. Na Espanha, do mesmo modo, a utilização do meio eletrônico pressupõe que o interessado possua assinatura e certificado digitais ${ }^{11}$. Já nos Estados Unidos, assim como ocorre no Brasil, existem serviços de peticionamento eletrônico sem a necessidade de certificado digital (ATHENIENSE, 2010, p. 69-80).

\section{Críticas aos Sistemas de Credenciamento}

No âmbito dos sistemas de credenciamento, a Lei no. 11.419/2006 estabelece em seu art. $2^{\circ}$, caput e $\S 11^{\circ}$, que:

Art. 2․ O envio de petições, de recursos e a prática de atos processuais em geral por meio eletrônico serão admitidos mediante uso de assinatura eletrônica, na forma do art. 10 desta Lei, sendo obrigatório o credenciamento prévio no Poder Judiciário, conforme disciplinado pelos órgãos respectivos.

$\S 10$. O credenciamento no Poder Judiciário será realizado mediante procedimento no qual esteja assegurada a adequada identificação presencial do interessado.

Novamente, verifica-se que há uma inexatidão na lei em questão, eis que estabelece como obrigatório o credenciamento prévio no Poder Judiciário. Essa inexatidão se dá em dois aspectos, quais sejam, no que tange à inovação processual trazida pelo credenciamento em si, bem como no que se refere à necessidade de comparecimento pessoal junto ao Poder Judiciário, mesmo daqueles interessados que optarem pela assinatura digital certificada.

\section{Necessidade de credenciamento, inovação processual e inconstitucionalidade}

10 Note-se que, embora o Superior Tribunal de Justiça exija a assinatura digital baseada em certificado digital, o Supremo Tribunal Federal, bem como o Conselho Nacional de Justiça e os Tribunais Regionais Federais possibilitam o peticionamento mediante simples identificação com login e senha (ATHENIENSE, 2010, p. 131-132).

11 Interessante notar que na Espanha, como salienta Ros (2010, p. 25), a legislação em certo momento criou certa "confusão" uma vez que estabeleceu que documento eletrônico era aquele produzido eletronicamente e assinado digitalmente (mediante a certificação digital). 
$\mathrm{O}$ art. $2^{\circ}$ da lei em comento, acima transcrito, ao prescrever que a prática de atos processuais por meio eletrônico depende de credenciamento prévio junto ao Poder Judiciário criou um impasse, uma vez que instituiu uma condição inexistia no processo comum, de papel.

Essa exigência de credenciamento dos profissionais para que possam atuar em determinado tribunal não existe para o processo de papel, motivo pelo qual, nas palavras de Calmon (2008, p. 67), "não seria o caso de se adotar prática diversa para a petição eletrônica, pois a lei não veio mudar as regras do jogo, mas apenas para disciplinar o uso da informática, para facilitar o andamento dos processos".

Além do mais, Costa e Marcacini (2002), antes mesmo da edição da lei em comento, já alertavam para o fato de que tanto os advogados, quanto o membros do Ministério Público teriam de se "credenciar" junto ao Poder Judiciário, e que tal credenciamento não tem o conteúdo de mero cadastramento, mas sim significado bem mais amplo, que envolve autorização, habilitação e capacitação. Isto significaria dizer que o advogado, o promotor, o defensor público, enfim, todos os participantes do processo, para peticionar, precisariam pedir autorização ao Poder Judiciário.

Paula (2010, p. 85) afirma que caso fosse aceita a hipótese do credenciamento obrigatório, estaríamos diante da "esdrúxula hipótese de um advogado necessitar comparecer a um setor específico do órgão jurisdicional para cadastramento, apresentando sua identidade profissional, comprovando sua condição para que pudesse peticionar", o que certamente configuraria violação de prerrogativas de advogados e promotores e furtar-lhesia funções legalmente constituídas.

Essa exigência de credenciamento encontra-se em discussão perante o Supremo Tribunal Federal, na ADI 3880, promovida pelo Conselho Federal da Ordem dos Advogados do Brasil, onde o art. 2으, caput, e diversos outros dispositivos da lei estão sendo questionados.

No que diz respeito à questão em tela, perfilha-se aqui o mesmo entendimento exarado pelo autor da referida ação direta, ou seja, de que o dispositivo que transfere ao Poder Judiciário a possibilidade de controlar quem pode ou não advogar é inconstitucional, eis que contrário ao art. 133, da Constituição. 
Conforme nos leciona Atheniense (2010, p. 135), a Constituição, ao atribuir dignidade constitucional à advocacia, "inserindo-a como função essencial à administração da justiça, afastou o ordenamento dos advogados das Cortes Judiciárias", de modo que o credenciamento previsto na lei para o exercício profissional "menoscaba a atividade, sujeitaa administrativamente aos tribunais, ensejando que advogados venham a ser afastados de suas atividades por atos de órgãos em face dos quais detêm independência constitucionalmente estabelecida".

Registre-se, assim, que pelos motivos elencados acima, diverge-se, neste aspecto, de Almeida Filho, quando este defende no petitório que subscreve na qualidade de advogado e presidente do Instituto Brasileiro de Direito Eletrônico (amicus curiae na ADIn $3880^{12}$ ), que "a necessidade de credenciamento do usuário junto ao Poder Judiciário tem como elemento a garantia de que a parte possui capacidade postulatória" ${ }^{13}$, tendo em vista que essa exigência extrapola os requisitos estabelecidos pela Lei no. 8.906/1994 para o exercício da advocacia.

\section{Obrigatoriedade do credenciamento mesmo para os optantes pela assinatura digital}

Além das questões suscitadas, conforme salientado no item acima, o art. 10, § 2으, III, da Lei no. 11.419/2006, admitiu dois sistemas de identificação do usuário a saber: assinatura digital (alínea "a") ou cadastro de usuário-senha junto ao respectivo órgão do Poder Judiciário (alínea "b"). Todavia, o art. 2o acima transcrito "fecha essas possibilidades ao dispor que mesmo o usuário que tenha optado pela alínea 'a' - assinatura digital - terá que se credenciar em cada tribunal para atuar por meios eletrônicos, o que anula por completo o dispositivo anterior" (CALMON, 2008, p. 63).

Com efeito, indaga-se: existe razão para que os usuários que se utilizarem da assinatura digital certificada credenciarem-se pessoalmente junto aos sistemas a serem criados pelos tribunais? A resposta, evidentemente, é negativa, eis que para a concessão da

12 Ação Direta de Inconstitucionalidade, ainda em trâmite, na qual a OAB questiona a constitucionalidade de diversos dispositivos da Lei em estudo, inclusive o art. $2 \stackrel{\circ}{\circ}$, ora criticado.

13 BRASIL. Supremo Tribunal Federal. Ação Direta de Insconstitucionalidade no 3880. Requerente: Conselho Federal da Ordem dos Advogados do Brasil. Relator: Ricardo Lewandowski. Manifestação do Instituto Brasileiro de Direito Eletrônico na qualidade de amicus curiae. Disponível em: <http://www.slideshare.net/processoeletronico/amicus-curiae-adin-3800>. Acesso em: 13 out. 2010. 
certificação digital é necessário o comparecimento pessoal do interessado perante a entidade pública definida na lei específica, como abordado anteriormente.

Não bastasse, parece ilógico imaginar a obrigatoriedade do titular de uma assinatura digital baseada em certificado digital comparecer antecipadamente perante todos os destinatários de um documento eletrônico a ser firmado por este meio, com o objetivo de garantir sua autenticidade, "o que não é seu intuito e contrariaria seu objetivo nuclear. A tecnologia dispensa tal formalidade, pois garante de per si segurança e autenticidade para validação de informações eletrônicas" (PAULA, 2010, p. 85).

Assim, caso se admita esse sistema de identificação previsto na alínea " $b$ ", do art.

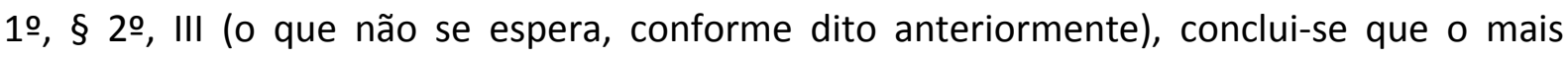
razoável seria exigir o comparecimento pessoal para fins de credenciamento apenas dos advogados que não possuírem assinatura digital, tendo em vista se tratar de diligência totalmente desnecessária daqueles que já se encontram certificados digitalmente por entidade credenciada e fiscalizada.

Note-se que essa medida é adotada, por exemplo, pelo Tribunal Superior do Trabalho, que mediante a Instrução Normativa 30/2007 ${ }^{14}$, buscando aprimorar a falha na legislação em comento, estabelece em seu art. 4으, $\S \S 2$ ㅇ e 3ㅇque:

Art. 4ㅇ. § 2ㅇ. No caso de assinatura digital, em que a identificação presencial já se realizou perante a Autoridade Certificadora, o credenciamento se dará pela simples identificação do usuário por meio de seu certificado digital e remessa do formulário devidamente preenchido.

§ 3․ No caso da assinatura cadastrada, o interessado deverá comparecer, pessoalmente, perante o órgão do Tribunal no qual deseje cadastrar sua assinatura eletrônica, munido do formulário devidamente preenchido, obtendo senhas e informações para a operacionalização de sua assinatura eletrônica.

De acordo com Paula (2010, p. 85), o referido tribunal adota a diretriz mais correta, exigindo a presença do interessado somente naqueles casos em que se utilize o sistema usuário-senha, sendo que se espera a adoção de caminho similar por outros órgãos do Poder Judiciário, pois, caso isso não ocorra, importará na manutenção das dificultosas e onerosas condições para ajuizamento de ações em comarcas distintas do domicílio do interessado, "dificultando o ingresso em juízo, mantendo o nefasto retrocesso vivenciado, responsável

\footnotetext{
${ }^{14}$ Referida Instrução Normativa regulamenta a Lei no. 11.419/2006 no âmbito da Justiça do Trabalho.
} 
pelo afastamento da população deste órgão com função essencial e indispensável à pacificação social".

Destaque-se, ainda, a solução apontada por Reinaldo Filho (2007, p. 2), que afirma que o ideal seria que os órgãos dos diversos segmentos do Poder Judiciário implantem sistemas de credenciamento baseados em certificação digital, pois os interessados, nesse caso, já passaram pela identificação presencial no momento do registro perante a autoridade certificadora (autoridade vinculada à ICP-Brasil), "podendo assim, dos computadores de suas residências e locais de trabalho, acessar os sistemas e fazer o credenciamento em todo e qualquer tribunal, evitando as inconveniências de um (novo) deslocamento físico", o que corrobora o alegado.

\section{Críticas aos Sistemas Destinados para a Prática de Atos Processuais}

No que se refere às plataformas eletrônicas para a transmissão de petições, a doutrina aponta outras duas inconsistências no texto legal, relativas à ausência de obrigatoriedade na criação de um sistema destinado para a prática de atos processuais padronizado e quanto à falta de compatibilidade entre os diversos sistemas passíveis de serem criados pelos órgãos do Poder Judiciário.

\section{Diversidade de Sistemas Destinados para a Prática de Atos Processuais}

Outra crítica a ser abordada no presente estudo é a que diz respeito à possibilidade de cada um dos órgãos do Poder Judiciário criar seu próprio sistema eletrônico para transmissão de petições e prática de atos processuais.

Consoante as redações do caput $^{15}$, do art. $2^{\circ}$ e do $\S 3^{0^{16}}$, do mesmo artigo, é possível se constar que a Lei no. 11.419/2006 autorizou os tribunais e ramos da justiça a desenvolverem seus próprios sistemas para realização de atos processuais em meio eletrônico, sem a necessidade de adoção de um sistema padronizado. Com efeito, ante a

\footnotetext{
15 “Art. 2‥ 0 envio de petições, de recursos e a prática de atos processuais em geral por meio eletrônico será admitido mediante uso de assinatura eletrônica, na forma do art. 1으, sendo obrigatório o credenciamento prévio junto ao Poder Judiciário conforme disciplinado pelos órgãos respectivos". Note-se que a parte final do dispositivo autoriza os tribunais a disciplinarem quanto aos sistemas a serem utilizados na forma que thes convierem.

16 “Art. 2ㅇ. § 3‥ Os órgãos do Poder Judiciário poderão criar um cadastro único para o credenciamento previsto neste artigo".
} 
redação dos dispositivos citados, resta claro que se trata de medida facultativa a criação de um sistema eletrônico único para facilitar o acesso do postulante aos diversos órgãos jurisdicionais brasileiros.

Assim, por ser opcional ao órgão do Poder Judiciário, caso um tribunal não se filie a um sistema eletrônico único, não haverá medida que o obrigue à sua aceitação, "podendo ocasionar a bizarra, mas não impossível, hipótese de todo causídico que intentar utilizar a via eletrônica para tramitação processual, ter que se cadastrar individualmente junto a todos os órgãos jurisdicionais existentes em cada comarca ou Estado" (PAULA, 2010, p. 87).

Entretanto, como se sabe, nos dizeres de Abrão (2009, p. 21), "de nada adianta disciplinar o mecanismo trazido pela lei que cuida da informatização do processo, sem que haja um sistema próprio padronizado, evitando assim que cada Justiça se socorra de suas próprias ferramentas, sem espelhar uma orientação unívoca", o que não vem se verificando na prática, onde já existem diversos sistemas eletrônicos adotados pelos diferentes órgãos do Poder Judiciário.

Quanto à diversidade de sistemas, Reinaldo Filho (2007, p. 2) cita os seguintes exemplos:

A Justiça do Trabalho, que já tem seu sistema informático para transmissão de petições (o 'e-DOC', baseado em assinatura digital), que foi desenvolvido para usuários que tenham interesse ou sejam partes em processos que tramitam nesse ramo da Justiça. A Justiça Federal, por sua vez, também já desenvolveu o seu próprio modelo de processo eletrônico para os Juizados Especiais (o 'e-Proc'), cujo acesso, para credenciamento, é feito através dos sites dos respectivos tribunais regionais federais. Alguns tribunais estaduais também desenvolveram sistemas próprios para tramitação total ou parcial de ações judiciais em meio eletrônico.

Esse quadro, segundo Araújo (2010, p. 129), "seguramente, não beneficia a ninguém, tendo-se como principais prejudicados os advogados, em especial os com pequenos escritórios, que atuam em diversos ramos em suas Comarcas", de modo que, caso persista a multiplicidade de sistemas que ocorre atualmente, certamente estará se contrariando objetivos primordiais da lei, tais como a facilitação do acesso à justiça e a segurança do processo eletrônico.

Diferentemente do que ocorre no Brasil, andou bem o Ministério da Justiça de Portugal que, através do projeto de "desmaterialização dos processos nos Tribunais Judiciais", preocupou-se em estabelecer a utilização de um sistema único para prática de 
atos processuais, denominado CITIUS $^{17}$, o que certamente significou um grande avanço para a implantação do processo eletrônico naquele país.

\title{
Falta de Interoperabilidade entre os Diversos Sistemas
}

Além dos prejuízos causados pela existência, por si só, de diversos sistemas para a prática de atos processuais em meio eletrônico, outro impasse surge no que tange à compatibilidade entre eles. Isto porque, não é muito difícil prever que a disseminação de diversos tipos de sistemas implicará na falta de interoperabilidade entre eles, ameaçando, segundo Leal (2006), o sucesso do modelo brasileiro de processo eletrônico.

O referido autor critica a lei de informatização do processo judicial neste ponto, uma vez que a legislação "pecou por não explicitar a importância do desenvolvimento dos sistemas de forma coordenada, convergente, com parâmetros técnicos bem definidos e compatíveis" (Leal, 2006). Segundo ele:

\begin{abstract}
Revela-se com intensidade a importância de um desenvolvimento uniforme dos sistemas informáticos de modo a viabilizar a interoperabilidade, a compatibilidade entre eles, sob pena de restar impraticável todo esse engenhoso e bem arquitetado mecanismo tecnológico de promoção da celeridade processual, acarretando a formação de 'ilhas informáticas' na Administração Pública, equívoco inescusável para um Estado que pretenda adotar, com êxito, práticas de e-government (LEAL, 2006).
\end{abstract}

No mesmo sentido é a lição de Reinaldo Filho (2007, p. 2), que prevê sem receios que os diversos sistemas a serem criados pelos órgãos do Poder Judiciário "não guardam interoperabilidade uns com os outros, já que os tribunais não estabeleceram um protocolo de comunicação único", gerando grande dificuldade para concretização do processo eletrônico no Brasil.

De acordo com os referidos autores, situação diferente ocorreu na Itália, onde o Decreto da Presidência da República no. 123/2001 estipulou inúmeras regras referentes ao processo eletrônico, inclusive no que se refere à adoção de um único sistema para todos os órgãos do Judiciário (LEAL, 2006; REINALDO FILHO, 2007, p. 2).

17 PORTUGAL. Ministério da Justiça. Portaria no. 114, de 6 de fevereiro de 2008. Disponível em: < http://www.tribunaisnet.mj.pt/PortariaCitius.pdf>. Acesso em: 10 nov. 2010. 
Na Espanha, do mesmo modo, prezou-se pela centralização da gestão dos planos de modernização, sendo que a interoperabilidade entre sistemas (interna e externamente) foi apresentada um dos pilares do modelo de informatização do processo judicial em andamento no país (FUNDACIÓN TELEFÓNICA, 2009).

Para viabilizar a denominada "jurisdição tecnológica" deverá existir uma verdadeira "malha digital", isto é, "rodovias eletrônicas de alta velocidade" que transportem os autos virtualmente, de forma instantânea, entre os diversos órgãos judiciais e entre estes e o interessado, sendo que, se os softwares dos diferentes Tribunais forem incompatíveis entre si, não se comunicarem, será impossível se conceber um verdadeiro processo eletrônico (LEAL, 2006).

Desse modo, muito embora o art. $14^{18}$, da Lei 11.419/2006, preconize a padronização dos sistemas a serem criados pelo Poder Judiciário, especialmente ante os inúmeros sistemas já existentes, é difícil crer que haverá efetivamente uma unificação entre os sistemas, o que certamente tornará mais custosa a vida não só de advogados, como também comprometerá etapas do processo eletrônico como, por exemplo, a remessa de recursos aos tribunais.

\section{Conclusão}

Diante de todo o exposto, pode-se concluir que a Lei no. 11.419/2006, em que pese tenha sido criada a fim de equalizar a questão da razoável duração do processo, garantida constitucionalmente (art. 5으, LXXXVIII, da Constituição), pecou em determinados aspectos cruciais no que se refere à identificação e credenciamento dos interessados a praticarem atos por meio eletrônico, bem como se equivocou ao passo de não ter obrigado os órgãos do Poder Judiciário a instituírem uma plataforma eletrônica de transmissão de petições única, padronizada.

Como se viu, tais questões, caso não regulamentadas coerentemente, podem comprometer a viabilidade do processo judicial eletrônico no Brasil, tendo em vista que o modelo exposto nos exatos termos da lei atual: a) coloca em risco a incolumidade das informações e documentos transmitidos por meio eletrônicos (em razão da adoção de

18 “Art. 14. Os sistemas a serem desenvolvidos pelos órgãos do Poder Judiciário deverão usar, preferencialmente, programas com código aberto, acessíveis ininterruptamente por meio da rede mundial de computadores, priorizando-se a sua padronização". 
sistemas de identificação que dispensam a assinatura digital certificada); b) gera impasses desnecessários com organizações de classe (ao instituir a obrigatoriedade de credenciamento junto ao Poder Judiciário); c) prejudica objetivos primordiais da lei, tais como a facilitação do acesso à justiça e a segurança do processo eletrônico (ao admitir a multiplicidade de sistemas destinados para a prática de atos processuais).

Diante disso, espera-se que as resoluções e atos normativos a serem editadas pelos tribunais pátrios solucionem essas situações, assim como ocorreu nos casos do Superior Tribunal de Justiça (conforme item 3.1.2 acima) e do Tribunal Superior do Trabalho (como exposto no item 3.2.2 supra). Além disso, nas palavras de Abrão (2009, p. 55), também caberá ao Conselho Nacional de Justiça, "como órgão regulador, solucionar conflitos, expedir normas e encontrar soluções para minimizar dúvidas na aplicação da lei e proporcionar maior efetividade e controle dos órgãos jurisdicionais na interpretação da Lei no. 11.419/2006".

\section{Referências}

ABRÃO, Carlos Henrique. Processo eletrônico: lei 11.419 de 19 de dezembro de 2006. 2. ed. São Paulo: Revista dos Tribunais, 2009.

ALMEIDA FILHO, José Carlos de Araújo. Processo eletrônico e teoria geral do processo eletrônico: a informatização judicial no Brasil. 3. ed. Rio de Janeiro: Forense, 2010.

ALVIM, J. E. Carreira; CABRAL JUNIOR, Silvério Nery. Processo judicial eletrônico. Curitiba: Juruá, 2008.

ARAUJO, Jorge Alberto. Comentários ao art. 12 da Lei 11.419/2006. In: CHAVES JÚNIOR, José Eduardo de Resende (Coord.). Comentários à lei do processo eletrônico. São Paulo: LTr. 2010. p. 124-132.

ATHENIENSE, Alexandre. Comentários à lei 11.419/06 e as práticas processuais por meio eletrônico nos Tribunais brasileiros. Curitiba: Juruá, 2010.

BRASIL. Lei no 11.419, de 19 de dezembro de 2006. Dispõe sobre a informatização do processo judicial; altera a Lei no 5.869, de 11 de janeiro de 1973 - Código de Processo Civil; e dá outras providências. Disponível em: <www.planalto.gov.br/ccivil_03/_ato2004-2006/ 2006/lei//11419.htm>. Acesso em: 23 out. 2010.

. Medida Provisória 2.200-2/2001, de 24 de agosto de 2001. Institui a Infra-Estrutura de Chaves Públicas Brasileira - ICP-Brasil, transforma o Instituto Nacional de Tecnologia da Informação em autarquia, e dá outras providências. Disponível em: 
<http://www.planalto.gov.br/ccivil_03/mpv/Antigas_2001/2200-2.htm>. Acesso em: 23 out. 2010.

. Superior Tribunal de Justiça. Resolução n. 1, de 10 de fevereiro de 2010. Diário da Justiça Eletrônico [do] Superior Tribunal de Justiça, Brasília, 11 fev. 2010. Disponível em: <https://ww2.stj.jus.br/infProc/init?\#>. Acesso em: 23 out. 2010.

Supremo Tribunal Federal. Ação Direta de Insconstitucionalidade no 3880. Requerente: Conselho Federal da Ordem dos Advogados do Brasil. Relator: Ricardo Lewandowski. Manifestação do Instituto Brasileiro de Direito Eletrônico na qualidade de amicus curiae. Disponível em: <http://www.slideshare.net/processoeletronico/amicuscuriae-adin-3800>. Acesso em: 13 out. 2010.

Tribunal Superior do Trabalho. Instrução Normativa n. 30, de 13 de setembro de 2007. Diário da Justiça, Brasília, 18 set. 2007. Disponível em:

<http://www.tst.gov.br/DGCJ/instrnorm/30.htm>. Acesso em: 23 out. 2010.

CALMON, Petrônio. Comentários à lei de informatização do processo judicial: lei no 11.419 , de 19 de dezembro de 2006. Rio de Janeiro: Forense, 2008.

COSTA, Marcos da; MARCACINI, Augusto Tavares Rosa. Duas óticas acerca da informatização dos processos judiciais. Jus Navigandi, Teresina, v. 6, n. 59, out. 2002. Disponível em: <http://jus2.uol.com.br/doutrina/texto.asp?id=3228>. Acesso em: 13 out. 2010.

CUNHA, Fabiana Aparecida; TATO, Samantha Alves. Comentários de Fabiana Aparecida Cunha e Samantha Alves Tato. In: CHAVES JÚNIOR, José Eduardo de Resende (Coord.). Comentários à lei do processo eletrônico. São Paulo: LTr. 2010.

FUNDACIÓN TELEFÓNICA. Las TIC en la Justicia del Futuro. Barcelona: Planeta, 2009. Disponível em: <http://www.fundacion.telefonica.com/debateyconocimiento/ media/publicaciones/LAS_TIC_EN_LA_JUSTICIA_DEL_FUTURO.pdf>. Acesso em: 1 nov. 2010.

LEAL, Augusto Cesar de Carvalho. A multiplicidade de credenciamentos e a falta de interoperabilidade dos softwares dos tribunais: ameaça ao sucesso do processo judicial telemático no modelo dogmático brasileiro. Jus Navigandi, Teresina, v. 11, n. 1268, dez. 2006. Disponível em: <http://jus.uol.com.br/revista/texto/9295>. Acesso em: 14 out. 2010.

MENKE, Fabiano. Assinaturas digitais, certificados digitais, infra-estrutura de chaves públicas brasileira e a ICP alemã. Revista de Direito do Consumidor, São Paulo, v. 48, n. 12, p. 134-136, 2003.

PAULA, Wesley Roberto de. Um contesto multiforme de acesso à prestação jurisdicional: art. 2으, a tramitação processual eletrônica. In: CHAVES JÚNIOR, José Eduardo de Resende (Coord.), Comentários à lei do processo eletrônico. São Paulo: LTr. 2010.

PORTUGAL. Ministério da Justiça. Portaria no 114, de 6 de fevereiro de 2008. Disponível em: <http://www.tribunaisnet.mj.pt/PortariaCitius.pdf>. Acesso em: 10 nov. 2010. 
REINALDO FILHO, Demócrito. A garantia de identificação das partes nos sistemas para transmissão de peças processuais em meio eletrônico. o modelo da Lei no 11.419/2006. Jus Navigandi, Teresina, v. 12, n. 1337, fev. 2007. Disponível em:<http://jus.uol.com.br/ revista/ texto/9545>. Acesso em: 13 out. 2010.

ROHRMANN, Carlos Alberto. A informatização do processo judicial segundo a Lei n. 11.419, de 19 de dezembro de 2006. Revista da Faculdade de Direito Milton Campos, Belo Horizonte, v. 16, p. 19-68, 2008.

ROS, Corazón Mira. El expediente judicial electrónico. Madri: Dykinson, 2010.

SOARES, Marcus Vinicius Brandão. Breve introdução à assinatura digital para operadores do direito. In: CHAVES JÚNIOR, José Eduardo de Resende (Coord.). Comentários à lei do processo eletrônico. São Paulo: LTr. 2010.

WAMBIER, Luiz Rodrigues; WAMBIER, Teresa Arruda Alvim; MEDINA, José Miguel Garcia. Breves comentários à nova sistemática processual civil, 3 : leis 11.382/2006, 11.417/2006, 11.341/2006, 11.419/2006, 11.441/2007 e 11.448/2007. São Paulo: Revista dos Tribunais, 2007. 